\title{
As cartas também constroem a história: potencialidades em uma conversa vinda do passado
}

[ Letters also build the history: potentialities in a conversation from the past

\section{Fernando Munhós ${ }^{\mathrm{I}}$}

- MONTE, Vanessa Martins do. Correspondências paulistas: as formas de tratamento em cartas de circulação pública (I765-I775). São Paulo: Fapesp, Humanitas, 20I5, 519 páginas.

A carta, enquanto gênero discursivo oferecido aos pesquisadores como fonte documental de outros tempos e espaços, cumpre papel de relevo nas ciências humanas. As diversas áreas do conhecimento preocupadas com o passado, distante ou próximo, terão nas missivas ricos vestígios, a partir dos quais se pode investigar um tempo que não é o nosso. O estudo da carta vem ganhando relevo nos estudos universitários nas últimas décadas. Como gênero pouco louvável, como escrita não ficcional - secundária na mentalidade editorial -, ou como portador da máxima maleabilidade que lhe é atribuível -, pode caminhar do estilo mais complexo e rebuscado ao mais simples e desleixado, sem nenhum entrave -, esse, que é dentre os dispositivos discursivos o mais comum e corriqueiro, foi também o mais subestimado. Não é como a poesia, que possui um valor "estético" em si, ou como o documento oficial, o despacho, produzido pelos poderes estatais e nacionais, de valor histórico inquestionável.

MUNHÓS, Fernando. As cartas também constroem a história: potencialidades em uma conversa vinda do passado. Revista do Instituto de Estudos Brasileiros, Brasil, n. 64, p. 336-342, ago. 2016.

DOI: http://dx.doi.org/Io.II6o6/issn.23I6-90IX.voi64p336-342

I Universidade de São Paulo (USP, São Paulo, SP, Brasil). 
Faço tal afirmação enquanto estudioso dos textos epistolares anteriores ao século XIX, iluminado pela razão e ofuscado pela ideia de subjetividade. Certa visão romântica que resiste ao longo do tempo privilegiou a guarda daqueles epistolários dos tidos por mais notáveis, como atividade quase de antiquário, que pressupõe preservar o íntimo da "inspiração". Mas, em se tratando do século XVIII, ou antes, o critério seria muito mais objetivo: aqueles bem-nascidos da sociedade estamental tinham recursos (políticos e financeiros) para erigir em seu testamentário algum local que preservasse seus papéis para a posteridade. Os exemplos são claros: obviamente as cartas do padre Antônio Vieira foram preservadas, depois de uma vida de feitos inquestionáveis²; ou mesmo as chamadas "cartas familiares" do grande poeta seiscentista d. Francisco Manuel de Melo não se perderam3; ou ainda, para irmos mais longe, o grande mercador português do século XVIII, Francisco Pinheiro, após uma vida de negócios e tratos com nobres e plebeus, conseguiu que a Congregação de Nossa Senhora da Doutrina, em Lisboa, preservasse as cartas que trocou por quase quatro décadas com sua trupe de caixeiros, parentes e amigos comerciantes 4 . Mas esse é o limite. Ou se era nobre, ou se estava próximo deles. Afora isso, (quase) não restou história para contar. Um gênero da escrita tão rico e presente em grande parte da história da humanidade não encontra correspondente relevância nos arquivos abertos para consulta no Brasil ou mesmo na velha Europa.

Não será oportuno, aqui e agora, avaliar moralmente o ato de publicação de cartas - papéis tão pessoais, que cumprem retoricamente seu dever normativo no ato da leitura pelo destinatário, seu público de fato. Também não me parece lugar, neste momento, para discutir a inquestionável relevância de analisar através da retórica as cartas anteriores ao Iluminismo que chegaram até nós. A obra focalizada nesta resenha não enseja proposta de análise interpretativa da carta setecentista enquanto ato ou monumento. Um de seus grandes méritos é a iniciativa de trazer a um público vasto o acesso a um dos raros casos de cartas trocadas por gente comum, no século XVIII, e que por felicidade do acaso não se perderam em definitivo.

Refiro-me à tese de doutoramento da filóloga e professora Vanessa Martins do Monte, agora disponível em livro - Correspondências paulistas: as formas de tratamento em cartas de circulação pública (I765-I775). Como resultado de sua pesquisa, a autora vem apresentar um conjunto de cartas da segunda metade do século XVIII de autoria da gente que se encontrava na distante e opaca capitania de São Paulo.

A proposta da autora é ler, apresentar e transcrever um conjunto de papéis denominados por ela "cartas da administração colonial em circulação pública lavradas entre I765 e I775" (p. I7). São 8I documentos dentre os quais 74 missivas trocadas entre os habitantes da região nesse período dos primeiros dez anos após a retomada da autonomia administrativa da capitania. Nesse intervalo de tempo, que

2 VIEIRA, Padre António. Obra completa. tomo I - epistolografia, v. I-V. Direção: José Eduardo Franco e Pedro Calafate. São Paulo: Edições Loyola, 20I4.

3 MELO, D. Francisco Manuel de. Cartas familiares. Prefácio e notas: Maria da Conceição Morais Sarmento. Lisboa: Imprensa Nacional, Casa da Moeda, I98I.

4 LISANTI FILHO, Luís. Negócios coloniais, uma correspondência comercial do século XVIII. Brasília: Ministério da Fazenda; São Paulo: Visão Editorial, I973. 5 v. 
corresponde ao governo de d. Luís António de Sousa Botelho Mourão (o conhecido Morgado de Mateus), por iniciativa do ministro de d. José I, o marquês de Pombal, a capitania passa por uma reforma estratégica visando ao incremento da defesa da parte sul do Estado do Brasil. Por essa razão, o período de governança de d. Luís é conhecido como um momento de intensa militarização das vilas paulistas e maior controle demográfico dos rincões habitados nessa pequena parte da América portuguesa.

A pesquisadora, dentre os diversos elementos passíveis de análise presentes nesses documentos, decide focar seu instrumental filológico nas chamadas "formas de tratamento" utilizadas para se dirigir aos diferentes destinatários das cartas. Diante da diversidade notável de níveis hierárquicos próprios da sociedade do antigo Estado português reproduzida ali naquela região - notam-se especialmente os diversos níveis dentro da ordem militar, eclesiástica e as pessoas ditas comuns, sobretudo homens brancos e livres se dirigindo a eles -, revela-se promissora a iniciativa de Vanessa de observar mais atentamente os modos de composição da salutatio epistolar como meio de compreender melhor aquela organização social específica, tão pouco estudada até hoje. Ao mesmo tempo, Vanessa apresenta os documentos oferecendo-os em seu mais amplo potencial para a pesquisa científica em diversas áreas das humanidades.

Ao propor uma "fotografia detalhada do que acontecia nas cartas setecentistas escritas pelos habitantes da capitania de São Paulo” (p. I8), Vanessa Martins do Monte divide seu trabalho em três partes. A primeira é dedicada ao cotejo entre algumas teses centrais da historiografia brasileira sobre o contexto paulista no quadro geral no Império português. Em uma fecunda iniciativa de apoiar uma interdisciplinaridade entre os campos da filologia e da história, a pesquisadora procura traçar o que denomina "perfil sociocultural" dos remetentes das cartas, em um período em que a Coroa procura recolocar a região no cenário estratégico de poderes do Império. A predominância de remetentes e destinatários constituintes da ordem dos militares se justifica no sentido da postura do governo pombalino de combate ao avanço dos espanhóis na parte sul da América, sendo necessário ter por pilares da estratégia de defesa territorial a preservação das fronteiras e a organização dos povoamentos regionais, reunindo a população nas vilas e cidades. Assim, ao nomear Morgado de Mateus como governador da capitania, prioriza o papel dos militares na administração regional, colocando a ordem no centro das questões locais de governança.

A escolha da autora, ao iniciar a apresentação de sua pesquisa por uma análise historiográfica da região paulista no período de domínio português na América, mostra-se relevante. A filóloga centra-se no sentido da colonização de Caio Prado Jr., presente na Formação do Brasil contemporâneo, de I942. Origem do conceito de Antigo Sistema Colonial, formulado por Fernando Antônio Novais algumas décadas mais tarde, a tese de Caio Prado Jr. entende o atraso econômico brasileiro como resultado do papel exercido pela colônia como apêndice de uma metrópole interessada apenas no exclusivo, fruto do Pacto Colonial. Em I979, Novais toma esse sistema como uma peça da engrenagem do mercantilismo europeu, visto em direção ao desenvolvimento pleno 
do capitalismo no século XIX ${ }^{5}$. Tão válidos quanto esse viés, contam-se igualmente as propostas interpretativas que fazem frente a essa visão, focando nas análises do desenvolvimento interno das capitanias portuguesas, ou os estudos que pensam o território português na América como um contexto que vai além do papel de simples apêndice de Portugal, focando nas distribuições e delegações dos poderes políticos da Coroa, ou ainda a partir de pesquisas recentes que demonstram a existência de um mercado interno na Colônia, já no século XVII'.

Desse exercício de caráter histórico nasce ainda, no primeiro capítulo da tese da autora, uma categorização detalhada da temática dos documentos, citando os assuntos das cartas, além dos perfis de alguns dos remetentes, possíveis de se traçar a partir de pesquisa em arquivos e obras de genealogia. Longe de querer "homogeneizar" as cartas, a autora procura, na atividade de categorizar temas, remetentes e destinatários, encontrar as questões que balizam a produção e circulação dos textos. A partir dessa atividade, percebeu-se uma maioria de remetentes militares vindos de contextos familiares de nascidos no território americano já há diversas gerações.

A interpretação histórica é ponto de partida para a apresentação de um conjunto documental que não se deixa contaminar por visões posteriores à sua produção, $\mathrm{e}$ que será detalhado no capítulo seguinte do livro. A segunda parte explora o corpus à luz da filologia e da paleografia. A autora procura relacionar o instrumental aos manuscritos focalizados em sua pesquisa, legitimando a escolha dos 8I documentos em face do conjunto de mais de I3 mil peças do arquivo da coleção Morgado de Mateus. Responder perguntas como "por que essas cartas?" ou "por que as formas de tratamento e não outras características?" foi objeto de sua atenção no minucioso trabalho de descrição codicológica do suporte (papel), considerando as filigranas existentes (marcas d'água), o número de pontusais, as dimensões das margens esquerdas dos textos, os graus de aproveitamento das folhas para a escrita etc. Os dados levantados são precisos e detalhados. Levando em conta o fato de que, como a autora mesmo afirma, a presença dessas informações ali se justifica pois são voltadas "a um público que provavelmente não irá ter contato físico com as fontes" (p. II2), cabe ao pesquisador interessado, dotado de seu instrumental específico, interpretá-los e ajuizá-los, seguindo os critérios responsáveis dentro de seu campo de trabalho, seja a filologia, a história, a retórica etc. E assim também o faz Vanessa, que, para além do trabalho exaustivo de categorização e comparação dos dados, igualmente os interpreta a partir de seu referencial teórico, a filologia. Por exemplo: os graus de aproveitamento dos papéis das cartas estão ali, e são dados, assim como as dimensões

5 Ver PRADO Júnior, Caio. Formação do Brasil contemporâneo - Colônia. São Paulo: Brasiliense, I96I; NOVAIS, Fernando Antônio. Portugal e Brasil na crise do Antigo Sistema Colonial (I777-I808). São Paulo: Hucitec, I985.

6 Sobre essas perspectivas diversas cito, por exemplo: MATTOSO, José (Org.). História de Portugal: o antigo regime. Lisboa: Editoral Estampa, I993, v. 4; MONTEIRO, Nuno Gonçalo; CARDIM, Pedro; CUNHA, Mafalda Soares da (Org.). Optima Pars: elites ibero-americanas do antigo regime. Lisboa: Imprensa de Ciências Sociais, 2005; FLORENTINO, Manolo. Em costas negras: uma história do tráfico entre a África e o Rio de Janeiro. (séculos XVIII e XIX). São Paulo: Companhia das Letras, I997; FRAGOSO, João Luís Ribeiro; GOUVÊA, Maria de Fátima (Org.). Na trama das redes. Política e negócios no império português, séculos XVI-XVIII. Rio de Janeiro: Civilização Brasileira, 20I0. 
do texto e sua orientação em relação às dobras e sobrescritos. Essas informações são riquíssimas em se tratando de dispositivos de um tempo tão longínquo. Mas daí a relacioná-las a categorias ditas universais como habilidade $x$ inabilidade de escrita já deve ser de responsabilidade da área específica do conhecimento a que elas se relacionam - no caso, a filologia. O critério classificatório é sempre do pesquisador, orientado pela razão pragmática da ciência pós-iluminista e não deles, homens e mulheres do século XVIII.

Vanessa Martins do Monte torna essa distinção bem clara em seu livro, demonstrando grande responsabilidade no ato de edição das cartas. A autora não deixa os dados e os juízos se confundirem na síntese de sua pesquisa. A análise codicológica, seguida da análise paleográfica das formas de tratamento presentes nas cartas, está muito bem estruturada. Ambas se revelam, inclusive, muito importantes para o ato de edição semidiplomática do corpus, que finaliza essa segunda parte do trabalho. A autora oferece valioso presente aos leitores anexando ao volume um CD-ROM contendo a versão digitalizada de todas as cartas do corpus. Favorece, assim, não apenas historiadores interessados no século XVIII português, como filólogos e pesquisadores da língua portuguesa.

A terceira parte do livro, voltada propriamente à análise das formas de tratamento contidas nas cartas, apresenta a síntese dos dados levantados na pesquisa e a comparação com as conclusões presentes no levantamento bibliográfico realizado pela autora sobre o tema. Desse exercício, pôde inserir sua análise na fortuna crítica do assunto (p. 4I3), fazendo com que suas percepções críticas sobre as formas de tratamento estudadas a partir do corpus da pesquisa dialoguem com o que vinha se afirmando sobre as transformações da língua em Portugal e no Brasil, objeto de estudo, pelo menos desde José Leite de Vasconcelos em fins do século XIX7. Nessa bibliografia sobre as variações do português no tempo, a autora conclui que é quase consenso haver forte relação entre a necessidade de adequação da fala/escrita para a comunicação entre camadas sociais diferentes e as transformações das formas nominais de tratamento no decorrer da história da língua. A necessidade de se dirigir a alguém hierarquicamente superior na sociedade colonial, por exemplo, está diretamente ligada à evolução da locução pronominal vossa mercê para você no contexto brasileiro. É o que afirmam os estudos. Paralelamente, a estudiosa enriquece a discussão, pois acrescenta o dado empírico relevante de que existem "comportamentos distintos com relação à escolha do uso da forma de tratamento para se dirigir a um cargo mais elevado" (p. 447) a partir da categoria socioprofissional específica. Em outras palavras, ficou evidenciado na pesquisa que os termos usados dentro da ordem dos militares para se dirigir a um superior hierárquico seguem um critério específico que não é o mesmo dentro de outra ordem, como a eclesiástica, por exemplo.

A pesquisa de Vanessa insere-se no campo de estudos da filologia do português brasileiro. Seguindo os caminhos iniciados pelo professor Segismundo Spina ${ }^{8}$, a

7 VASCONCELOS, José Leite de. Dialectos extremenhos: contribuições para o estudo da dialectologia portuguesa. Revista lusitana, Lisboa, v. 5, , I897-99, p. I37-I47.

8 SPINA, Segismundo. Introdução à edótica. São Paulo: Edusp, I994. 
autora emprega grande acuidade no tratamento dos códigos linguísticos dos textos que pretende transcrever e publicar, sinalizando que, no trabalho de edição, é necessário se ater aos mínimos detalhes de sua composição e seguir fielmente os critérios científicos da transcrição. Um olhar mais atento ao trabalho editorial diria que esses códigos linguísticos constituem uma parte do caminho em direção à edição do texto, restando ainda o tratamento de seus códigos bibliográficos, entendidos como os elementos que oferecem um significado histórico e social do artefato ao longo de sua história, desde sua produção e primeira circulação9. Sob essa perspectiva, cabem algumas considerações. Primeiramente, a autora não se propõe a apresentar uma edição hermética do conjunto das cartas, como se transformasse o corpus em uma “obra literária” - um epistolário - que possuísse autonomia de circulação nas estantes das livrarias. Seu trabalho tenciona apresentar os manuscritos aos pesquisadores interessados que, porventura, não possam entrar em contato direto com os papéis no arquivo. Em segundo lugar, não parece objetivo da autora apresentar sua edição das cartas como sendo a única via de acesso do leitor aos documentos. É frequente a existência de edições de manuscritos antigos que se perderam, tornando aquela edição a única possibilidade de acesso ao texto. Mas não é o caso aqui. Sua transcrição, somada à reprodução fotográfica das cartas, torna o trabalho legítimo e consistente, pois o próprio leitor pode comparar a fotografia do manuscrito e a edição transcrita pela autora, ou até mesmo pode ir ao arquivo e examinar os papéis, disponíveis lá para a consulta.

Por fim, nessas três partes constituintes de sua tese - a localização histórica dos documentos, a análise paleográfica dos manuscritos e o estudo das formas de tratamento para o português brasileiro -, Vanessa Martins do Monte apresenta um trabalho em que desenha as diversas potencialidades de um corpus documental composto por cartas escritas no século XVIII. Ao contemplar a viabilidade dos manuscritos como fontes não somente para o campo da filologia, mas também para diversas outras áreas do conhecimento, a autora incentiva assim demais pesquisadores ao estudo de cartas, gênero de texto tão rico e encantador.

SOBRE O AUTOR

FERNANDO MUNHÓS é doutorando em Letras no Departamento de Letras Clássicas e Vernáculas da Faculdade de Filosofia, Letras e Ciências Humanas da Universidade de São Paulo.

9 Ao realizar, em sua tese, uma proposta de edição de códices da poesia atribuída a Gregório de Matos e Guerra, Marcello Moreira faz um apanhado crítico das teorias filológicas e das questões envolvendo o ato de editar e publicar manuscritos de tempos passados. MOREIRA, Marcello. Critica Textualis in Caelum Revocata?: uma proposta de edição e estudo da tradição de Gregório de Matos e Guerra. São Paulo: Edusp, 20II, p. 7I-I63. 


\section{REFERÊNCIAS BIBLIOGRÁFICAS}

FLORENTINO, Manolo. Em Costas Negras: uma história do tráfico entre a África e o Rio de Janeiro (séculos XVIII e XIX). São Paulo: Companhia das Letras, I997.

FRAGOSO, João Luís Ribeiro; GOUVÊA, Maria de Fátima (Org.). Na trama das redes. Política e negócios no império português, séculos XVI-XVIII. Rio de Janeiro: Civilização Brasileira, 2010.

LISANTI FILHO, Luís. Negócios coloniais, uma correspondência comercial do século XVIII. Brasília: Ministério da Fazenda; São Paulo: Visão Editorial, I973. 5 v.

MATTOSO, José (Org.). História de Portugal: o antigo regime. v. 4. Lisboa: Editoral Estampa, I993.

MELO, D. Francisco Manuel de. Cartas familiares. Prefácio e notas: Maria da Conceição Morais Sarmento. Lisboa: Imprensa Nacional, Casa da Moeda, I98I.

MONTEIRO, Nuno Gonçalo; CARDIM, Pedro; CUNHA, Mafalda Soares da (Org.). Optima Pars: elites ibero-americanas do antigo regime. Lisboa: Imprensa de Ciências Sociais, 2005.

MOREIRA, Marcello. Critica Textualis in Caelum Revocata?: uma proposta de edição e estudo da tradição de Gregório de Matos e Guerra. São Paulo: Edusp, 20II, p. 7I-I63.

NOVAIS, Fernando Antônio. Portugal e Brasil na crise do Antigo Sistema Colonial (I777-I808). São Paulo: Hucitec, I985.

PRADO Júnior, Caio. Formação do Brasil contemporâneo - Colônia. São Paulo: Brasiliense, I96I.

SPINA, Segismundo. Introdução à edótica. São Paulo: Edusp, I994.

VASCONCELOS, José Leite de. Dialectos extremenhos: contribuições para o estudo da dialectologia portuguesa. Revista Lusitana, Lisboa, v. 5, I897-99, p. I37-I47.

VIEIRA, Padre António. Obra completa. tomo I - epistolografia, v. I-V. Direção: José Eduardo Franco, Pedro Calafate. São Paulo: Edições Loyola, 20I4. 